\title{
ASSEMBLY LINE BALANCING IMPLEMENTATION IN MANUFACTURING INDUSTRY
}

\author{
IBEH MATTHEW IMAGWUIKE ${ }^{1}$, NWANKWOJIKE BETHRAND NDUKA ${ }^{2} \&$ NWADINOBI \\ CHIBUNDO PRINCEWILL ${ }^{3 *}$ \\ ${ }^{1,2}$ Department of Mechanical Engineering, Michael Okpara University of Agriculture, Umudike Nigeria
}

${ }^{3}$ Department of Mechanical Engineering, Abia State University, Uturu, Nigeria

\begin{abstract}
A wide range of the real world problems in industries are related to misbalances of the production line. In this paper, there is the demonstration of a practical approach to balance and synchronize a ceiling fan assembly line which is characterized by several manufacturing limitations. The Rank Positional Weight (RPW) which is a heuristic method was used to balance the ceiling fan motor assembly line of Nigerian Engineering Works Port Harcourt for performance improvement. Data collected for this research is based on primary information. This involved assigning the tasks or elements into work stations such that the cycle time was minimized from 0.729 min to 0.583 min. This in turn minimized the balance delay from $31 \%$ to $5 \%$ thereby maximizing the line efficiency from $69 \%$ to $95 \%$. This increased the possible output of the assembly line from 608 units to 823 units of the assembled ceiling fan motor without additional resources. The study recommends that the company should adopt the new production line design.

KEYWORDS: Assembly Line Balancing, Heuristic Method; Rank Positional Weight; Cycle Time, Balance Delay and Efficiency
\end{abstract}

Received: Jun 06, 2020; Accepted: Jun 26, 2020; Published: Jul 30, 2020; Paper Id.: IJMPERDJUN2020541

\section{INTRODUCTION}

The purpose and philosophy of any manufacturing firm is to be in business by maximizing the control of those factors that determine its efficiency and productivity [1].In addition, have quality product(s) and the capability to cope with customers' demands. The achievement of these goals are predicated on planning, controlling and measuring parameters related to the performance of the sector. Therefore, manufacturers should realize that performance depends on how well the production line is in term of output. Thus, Assembly Line Balancing (ALB) plays a vital function especially in the production line. This is because the installation of an assembly line requires large capital of investments. It is therefore important that such a system is designed and balanced so that it is able to work as efficiently as possible. As part of manufacturing system, an assembly system performs a set of sequential distinct minimum rational work (task) for the assembly of a product and it consists of a set of work stations linked together by transport mechanism and detailed specification of how the assembly of the product flows from one station to another. It comes crucially important for the manufacturing system and assembly line since the process need to be optimized with the correct sequence order [2].

The success of achieving the goal of production is influenced significantly by balancing assembly lines [3]. Line Balancing means balancing the production line, or any assembly line. The main objective of line balancing is to distribute the task evenly over the work station so that idle time of man, of machine can be minimized. Line balancing primary focus at grouping the facilities or workers in an efficient pattern in order to obtain an optimum or 
most efficient balance of the capacities and flows of the production or assembly processes [4]. Therefore assembly line balancing problem can be said to be an optimization problem [5]. Assembly Line Balancing (ALB) is the term commonly used to refer to the decision process of assigning tasks to workstations in a serial production system. The task consists of elemental operations required to convert raw material in to finished goods. Toward the optimization subject, the most common variables are: The number of workstations necessary to execute all tasks; the maximum processing time that can be assigned to a single workstation (cycle time). The amount of time that one station execute no tasks (idle time) [6].By managing an assembly line, few advantages occur; such as better labour and machine utilization, easy learning for workers, less work-in-progress inventory, less space requirement and reduction in production costs [7].

There are various techniques, which have been used for production line planning. It has been observed that the linear programming, fuzzy and stochastic programming, heuristic and simulation methods are the most common utilized methods in the real problems of production and assembly lines balancing [8]. Generally, the study on ALB has been classified into two classes either Simple Assembly Line Balancing (SALB) or General Assembly Line Balancing (GALB) $[9,10]$. Basically, the assembly line in the SALB category consist of a straight line workstation that connects each other for completing each assigned task before the final product is released. First, SALB type-1 (SALB-1) problem consists of assigning tasks to minimize the number of workstation with fixed cycle time. While for SALB type-2 (SALB2), the objective is to minimize the cycle time with fixed workstation number [11]. Next is SALB for type-E problem which generally focus to maximize the line efficiency. Here, it is believed to consider both objectives on SALB type-1 and type-2 to maximize the assembly line efficiency. The GALB includes the problem such as the Two Sided Assembly Line Balancing (2S-ALB) that needs to operate the assembly in two serial connected assembly line with parallel formation [12, 13, 14].There is also the Mixed-model Assembly Line Balancing (MALB) problem which consider to assign the tasks into the workstation with different duration of time and different model to balance the assembly line[15]. Besides that, the Ushaped Assembly Line Balancing (UALB) arranged the tasks in a narrow U workstation outline as the assembly layout. For the U-shaped ALB, each worker is allowed to complete his job on either side of the U-line. The U-shaped layout is able to shorten the line length and improve the space utilization. Therefore, UALB are practically suitable for a production system with a small space of assembly line.

This paper considered the single model assembly line balancing problem (SALB), which can implement heuristics methods. These are simple computing methods that have been used to obtain optimal solutions of assembly line balancing problems [16]. There are some recent studied which compared some heuristics methods such as; Largest Candidate Rule (LCR), Kilbridge and Wester (K-W), and Rank Positional Weight (RPW). [17] reported in their study on imitating of two stages gear box procedure that the Rank Position Weight has been found very handy even when less data is available. This was done using the three methods of LCR, K-W and RPW to select the best method on minimum assembly time with better performance of essential retailing cost. This research also has found that RPW is the best method compared to other two. In addition, the bottleneck problems in most assembly lines have proved to be reduced through this RPW approach $[18,2]$.

This research is considering an assembly line producing ceiling fan motor. The ceiling fan motor assembly line of Nigerian Engineering Works Port Harcourt was observed to be experiencing a technical problem of high idle time, high labour cost and low line efficiency. This problem was attributed to imperfect allocation of work along various workstations. This makes for an unbalanced and inefficient line, which tend to reduce the overall productivity of the 
company. Therefore the objective of this work is to group the tasks into a given number of workstations such that the cycle time (the maximum of the sum of tasks times of the workstations) is minimized. This in turn maximizes the production rate and improved the efficiency of the line. This was achieved using the Rank Positional Weight (RPW) which is a heuristics method for this balancing problem because it offers a real practical tool which can be understood and applied. In addition, this study creates assembly line which have the highest line efficiency and to reveal the applicability of heuristic assembly line balancing methods for an optimal ceiling fan motor assembly line.

\section{METHODOLOGY}

In this study, the production of ceiling fan motor assembly in Nigeria Engineering Works Port Harcourt was investigated to solve the problem of assembly line balancing. The technological precedence diagram of the assembly line is shown in figure 1. The nodes correspond to the tasks that are involved in the assembly line; the arrows stands for the precedence relationship. Time is a very important factor and this can be shown on the diagram by numbers, representing units of time written adjacent to the task symbol. The unit of time in this work is in minutes. The objective of this research work is to minimize cycle time (maximizing the output rate) for a given number of workstations. The cycle time for a line (time between completion of successive items on the line) is determined by the maximum workstation time of the line. The required output of the line determines the cycle time of the line.

The cycle time is computed from the given production volume per shift using the following formula:

$$
\text { Cycle time }=\frac{\text { Efferive time avallable per shift }(T)}{\text { Production volume per shif }(Q)}
$$

The total idle time (IT) for the line is given by

$$
I T=n c-\sum_{i=1}^{k} t_{i}
$$

A line is perfectly balanced if IT $=0$ at the minimum cycle time.

Sometimes the degree to which a line approaches this perfect balance is expressed as a percentage or a decimal called the balance delay (B.D). As a percentage, the balance delay is given by:

$$
B . D=\frac{\text { ldle time of all workatations }}{\text { Avaitable working time for all stations }}=\frac{100(T)}{n e}=\frac{\left(n \varepsilon-\Sigma_{i=1}^{k i} z_{i}\right) \times 100}{n e}
$$

Therefore the balancing efficiency of the line is given by

Balancing efficient of line

$$
E=100-B \cdot D
$$

Equally balancing efficiency of the solution of the line balancing problem is given by the formula:

$$
\text { Balancing efficiency }=\frac{\text { Sum of all task timfs }}{\text { Number of workstations \& oyeletime }}=\frac{E_{i=1}^{k} \omega_{1} \times 100}{n e}
$$

A well balanced line has a very low balance delay. Therefore the balance delay is a measure of the efficiency of the line. 
The smoothness index (S.I) is a measure of how much station times deviates from the cycle time. It is called line standard deviation which is a measure of deviation from the mean. It is given as

$$
S . I .=\sqrt{\sum_{i=1}^{k}\left(C-t_{i}\right)^{2}}
$$

The line with high smoothness index has more inbuilt idle time. Therefore, the line with the smallest smoothness index has better efficiency.

The minimum number of workstations required in assembly line, $\mathrm{n}_{\min }$ is the sum of all the element times divided by the cycle time, and taken to the next highest integer.

$$
\boldsymbol{n}_{\min }=\frac{\sum_{i=1}^{h} t_{i}}{\theta} \text { (to nexthighest integer) }
$$

\section{Rank Positional Weight (RPW)}

The heuristic method was developed by Helgeson and Birnie of the General Electric Company in 1961 [19]. In this method, the ranked positional weight value of each operation is determined. The positional weight of a task or element is defined as the sum of that element time plus the times of all succeeding elements. Each element therefore has its positional weight and these are ranked so that the highest positional weight has rank 1, the next highest rank 2 and so on through the list of elements. Where two or more elements have the same positional weight they can be marked in the order they are found down the list.

The ALGORITHM for assignment of elements of work stations is carried out in the following manner:

- The element with the highest positional weight (or rank 1) is assigned to the first workstation.

- The time difference, Dt, between the assigned element time $\mathrm{a}_{\mathrm{i}}$ and the cycle time, $\mathrm{c}$, is

$$
D t=c-a_{i}
$$

- The element with the next highest positional weight or lowest rank is then selected and also checks made on it.

- Precedence: only elements which have all their proceeding elements assigned can be considered.

- The element time must be equal to or less than the unassigned work station time Dt calculated in (ii) i.e.

$$
a_{i+t} \leq D t
$$

If conditions (a) and (b) are met then the element is assigned to the first work station and (i) and (ii) are repeated for the element with the next lowest ranks. If one or both conditions (a) and (b) above are not met then that element is left and passed on to the next lowest rank and (a) and (b) for this element are checked.

- Items (ii) and (iii) are continued until there is no difference in time between the sum of the workstation assigned element times and cycle time (i.e. perfect balance), or it is not possible to assign any more element to the workstation because of precedence restrictions, or all the time of the remaining elements are greater than the unassigned station time. 
- Assignment to second workstation is then started by selection. Firstly, the element with the lowest rank or highest positional weight of the remaining unassigned elements.

- Items (ii), (iii), (iv) and (v) are thus continued until all the elements have been assigned to workstations

The Newcline ceiling fan motor assembly line comprises of nine workstations and 42 work elements or tasks as shown in Fig. 1. They include (1) dismantling of motor (2) decorative cap sub assembly (3) false cover subassembly (4) quality control run testing (5) regulation testing (6) cleaning and wrapping of motor (7) down rod sub assembly (8) canopy sub assembly (9) packing of motor with canopy, regulators and down rods. Each workstation has its elements or tasks as shown in Fig. 1 with the standard element time. The analysis of the assembly line before balancing was carried out to determine the efficiency performance index of the line. Then after balancing the assembly line by rank position method, which is a heuristic method, the efficiency performance index of the balanced line was also determined and the two results compared.

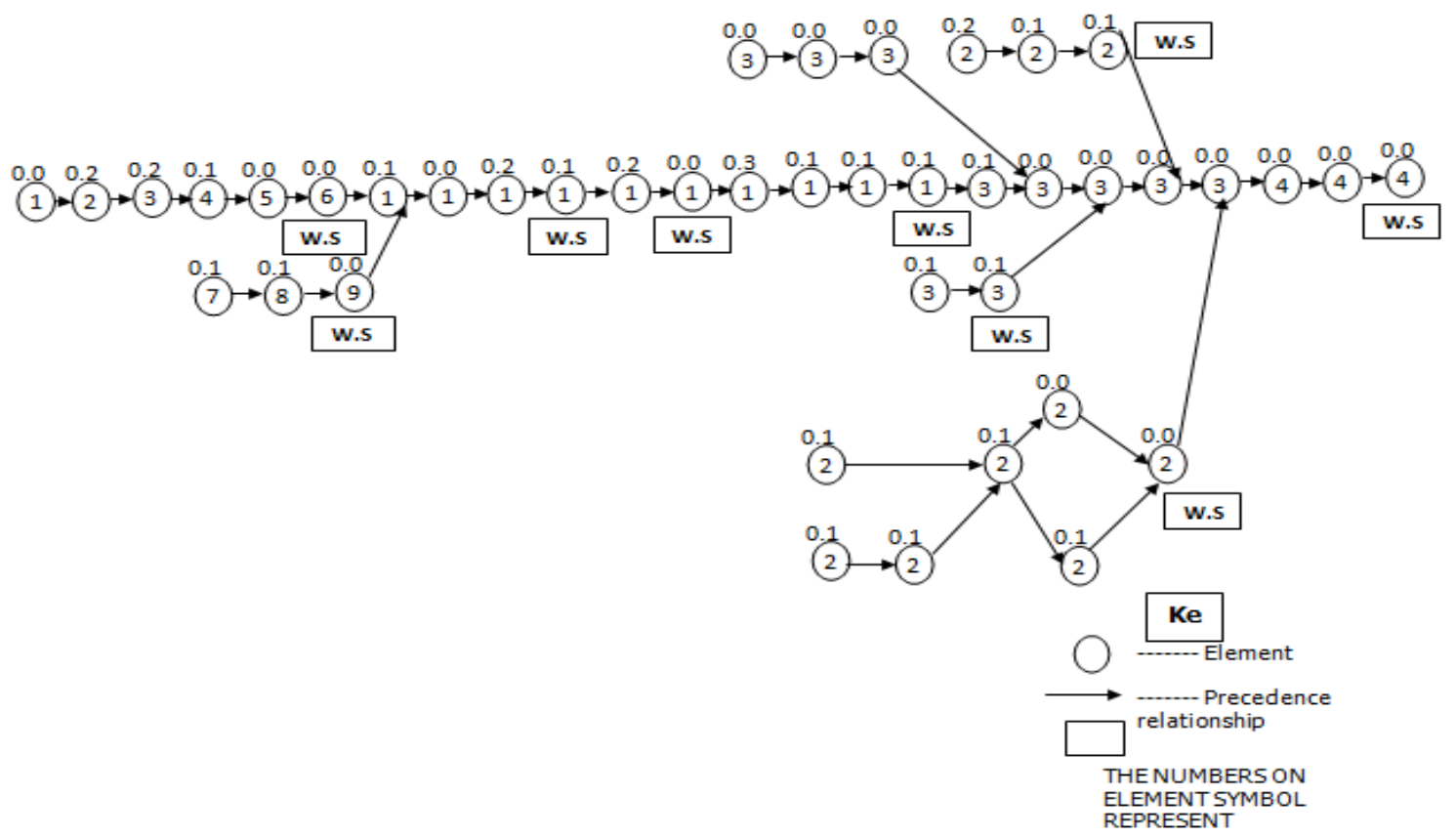

Figure 1: Precedence Diagram of Ceiling Fan Motor Assembling Line.

\section{RESULTS AND DISCUSSIONS}

Table 1: Summary Standard Time for N/C Ceiling Fan Motor Assembly Line

\begin{tabular}{|c|l|c|c|c|c|c|}
\hline S/N & Operations/Workstations & $\begin{array}{c}\text { Standard } \\
\text { Time Per } \\
\text { Piece (min) }\end{array}$ & $\begin{array}{c}\text { Number } \\
\text { Per Set } \\
(\mathbf{u n i t})\end{array}$ & $\begin{array}{c}\text { Total } \\
\text { Time } \\
(\mathbf{m i n})\end{array}$ & $\begin{array}{c}\text { Expected } \\
\text { Per set } \\
\mathbf{h r}\end{array}$ & $\begin{array}{c}\text { Production } \\
\text { Per Shift } \\
(\mathbf{x 8})\end{array}$ \\
\hline 1 & Dismantling of motor & 0.743 & 1 & 0.74 & 81 & 648 \\
\hline 2 & Decorative cap subassembly & 0.38 & 1 & 0.38 & 158 & 1248 \\
\hline 3 & False cover subassembly & 0.581 & 1 & 0.494 & 121 & 480 \\
\hline 4 & Quality control run testing & 0.31 & 1 & 0.31 & 194 & 1552 \\
\hline 5 & Regulator testing & 0.49 & 1 & 0.49 & 122 & 976 \\
\hline 6 & Cleaning and wrapping of motor & 0.712 & 1 & 0.712 & 84 & 672 \\
\hline 7 & Down rod subassembly & 0.792 & 1 & 0.792 & 76 & 608 \\
\hline 8 & Canopy subassembly & 0.28 & 1 & 0.28 & 214 & 1712 \\
\hline 9 & Packing of motor and & 0.699 & 1 & 0.699 & 86 & 688 \\
\hline
\end{tabular}


From Table 1, the ceiling fan motor assembly line efficiency performance index is calculated before balancing the line.

Total standard time to assemble motor and accessories $=4.987 \mathrm{~min}$.

Cycle time $=0.792 \mathrm{~min}$

Standard hourly production $=\frac{60}{0.792}=72$ wnits

Working hours per unit $=8$

Thus giving a line capacity of $\frac{60 \times 8}{0.792}=608$ units

The manpower for the line $=9$ men

The total idle time $($ IT $)$ for the line $=(9 \times 0.792)-4.897=2.23 \mathrm{~min}$

This is the in-built idle time in the system due to unbalanced workstation times.

The Balance Delay (B.D) of the line $=\frac{(9 \times 0.792-4.897) 100}{(9 \times 0.792)}=31 \%$

This is the percentage of inbuilt idle time in the line due to unbalanced workstation times.

Therefore, efficiency of the line $=100-31=69 \%$

Table 2: Workstations, Standard Element Time, Positional Weight and Ranks for N/C Ceiling Fan Motor Assembly Line

\begin{tabular}{|c|c|c|c|}
\hline Element & Standard Element Time (min) & Positional Weight (min) & Rank \\
\hline \multicolumn{4}{|l|}{ WST 1} \\
\hline 1 & 0.06 & 2.444 & 1 \\
\hline 2 & 0.223 & 2.389 & 2 \\
\hline 3 & 0.223 & 2.199 & 3 \\
\hline 4 & 0.165 & 2.009 & 5 \\
\hline 5 & 0.042 & 1.869 & 7 \\
\hline \multirow[t]{2}{*}{6} & 0.032 & 1.833 & 8 \\
\hline & 0.743 & & \\
\hline \multicolumn{4}{|l|}{ WST 2} \\
\hline 7 & 0.18 & 2,133 & 4 \\
\hline 8 & 0.153 & 1.98 & 6 \\
\hline \multirow[t]{2}{*}{9} & 0.047 & 1.85 & 9 \\
\hline & 0.38 & & \\
\hline \multicolumn{4}{|l|}{ WST 3} \\
\hline 10 & 0.146 & 1.81 & 10 \\
\hline 11 & 0.094 & 1.686 & 11 \\
\hline 12 & 0.20 & 1.606 & 12 \\
\hline \multirow[t]{2}{*}{13} & 0.141 & 1.436 & 13 \\
\hline & 0.581 & & \\
\hline \multicolumn{4}{|l|}{ WST 4} \\
\hline 14 & 0.258 & 1.316 & 14 \\
\hline \multirow[t]{2}{*}{15} & 0.047 & 1.096 & 15 \\
\hline & 0.305 & & \\
\hline \multicolumn{4}{|l|}{ WST 5} \\
\hline 20 & 0.235 & 0.687 & 20 \\
\hline
\end{tabular}




\begin{tabular}{|c|c|c|c|}
\hline 21 & 0.129 & $\begin{array}{l}0.487 \\
\end{array}$ & 26 \\
\hline \multirow[t]{2}{*}{22} & 0.129 & 0.377 & 32 \\
\hline & 0.493 & & \\
\hline \multicolumn{4}{|l|}{ WST 6} \\
\hline 16 & 0.306 & 1.056 & 16 \\
\hline 17 & 0.118 & $\begin{array}{l}0.796 \\
\end{array}$ & 17 \\
\hline 18 & 0.184 & 0.696 & 19 \\
\hline \multirow[t]{2}{*}{19} & 0.105 & 0.54 & 24 \\
\hline & 0.713 & & \\
\hline \multicolumn{4}{|l|}{ WST 7} \\
\hline 23 & 0.147 & 0.687 & 20 \\
\hline 24 & 0.125 & 0.765 & 18 \\
\hline 25 & 0.114 & 0.659 & 21 \\
\hline 26 & 0.199 & 0.562 & 22 \\
\hline 27 & 0.071 & 0.357 & 34 \\
\hline 28 & 0.122 & 0.401 & 30 \\
\hline \multirow[t]{2}{*}{29} & 0.094 & 0.297 & 36 \\
\hline & 0.792 & & \\
\hline \multicolumn{4}{|l|}{ WST 8} \\
\hline 30 & 0.14 & 0.547 & 23 \\
\hline \multirow[t]{2}{*}{31} & 0.142 & 0.428 & 29 \\
\hline & 0.282 & & \\
\hline \multicolumn{4}{|l|}{ WST 9} \\
\hline 32 & $\begin{array}{l}0.08 \\
\end{array}$ & 0.504 & 25 \\
\hline 33 & 0.047 & 0.43 & 28 \\
\hline 34 & 0.035 & 0.39 & 31 \\
\hline 35 & 0.106 & 0.45 & 27 \\
\hline 36 & 0.062 & 0.36 & 33 \\
\hline 37 & 0.047 & 0.307 & 35 \\
\hline 38 & 0.059 & 0.267 & 37 \\
\hline 39 & 0.047 & 0.0217 & 38 \\
\hline 40 & 0.082 & 0.177 & 39 \\
\hline 41 & 0.044 & $\begin{array}{l}0.107 \\
\end{array}$ & 40 \\
\hline \multirow[t]{2}{*}{42} & 0.082 & 0.07 & 41 \\
\hline & 0.698 & & \\
\hline
\end{tabular}

Table 3: Balanced N/C Ceiling Fan Motor Assembly Line

\begin{tabular}{|c|c|c|c|c|}
\hline Rank & $\begin{array}{c}\text { Element } \\
\text { Number }\end{array}$ & $\begin{array}{c}\text { Standard Element } \\
\text { Time (min) }\end{array}$ & $\begin{array}{c}\text { Difference Between Cumulative } \\
\text { Assigned Element Times and Cycle } \\
\text { Time (min) }\end{array}$ & Comment \\
\hline WST 1 & & & & 0.54 \\
\hline 1 & 1 & 0.06 & 0.317 & Assigned \\
\hline 2 & 2 & 0.223 & 0.94 & “ \\
\hline 3 & 3 & 0.223 & & \\
\hline & & $\mathbf{0 . 5 0 6}$ & 0.42 & " \\
\hline WST 2 & & & 0.255 & " \\
\hline 4 & 7 & 0.18 & 0.102 & " \\
\hline 5 & 4 & 0.165 & 0.06 & " \\
\hline 6 & 8 & 0.153 & 0.028 & " \\
\hline 7 & 5 & 0.042 & & 0.553 \\
\hline
\end{tabular}




\begin{tabular}{|c|c|c|c|c|}
\hline 12 & 12 & 0.20 & 0.113 & “ \\
\hline \multirow[t]{2}{*}{28} & 33 & 0.047 & 0.066 & “ \\
\hline & & 0.535 & & \\
\hline \multicolumn{5}{|c|}{ WST 4} \\
\hline 13 & 13 & 0.141 & 0.459 & “ \\
\hline 14 & 14 & 0.258 & 0.201 & “ \\
\hline 15 & 15 & 0.047 & 0.154 & “ \\
\hline \multirow[t]{2}{*}{18} & 24 & 0.125 & 0.029 & “ \\
\hline & & 0.571 & & \\
\hline \multicolumn{5}{|c|}{ WST 5} \\
\hline 16 & 16 & 0.306 & 0.294 & “ \\
\hline 17 & 17 & 0.118 & 0.176 & “ \\
\hline \multirow[t]{2}{*}{20} & 23 & 0.147 & 0.029 & “ \\
\hline & & 0.571 & & \\
\hline \multicolumn{5}{|c|}{ WST 6} \\
\hline 19 & 18 & 0.184 & 0.416 & “ \\
\hline 20 & 20 & 0.235 & 0.181 & “ \\
\hline 26 & 21 & 0.129 & 0.052 & “ \\
\hline \multirow[t]{2}{*}{31} & 34 & 0.035 & 0.017 & " \\
\hline & & 0.583 & & \\
\hline \multicolumn{5}{|c|}{ WST 7} \\
\hline 21 & 25 & 0.114 & 0.486 & " \\
\hline 22 & 26 & 0.119 & 0.367 & “ \\
\hline 34 & 27 & 0.071 & 0.296 & " \\
\hline 30 & 28 & 0.122 & 0.174 & " \\
\hline \multirow[t]{2}{*}{23} & 30 & 0.14 & 0.034 & “ \\
\hline & & 0.566 & & \\
\hline \multicolumn{5}{|c|}{ WST 8} \\
\hline 24 & 19 & 0.105 & 0.495 & “ \\
\hline 27 & 35 & 0.106 & 0.385 & " \\
\hline 29 & 31 & 0.142 & 0.247 & " \\
\hline 32 & 22 & 0.129 & 0.118 & " \\
\hline \multirow[t]{2}{*}{33} & 36 & 0.062 & 0.126 & " \\
\hline & & 0.544 & & \\
\hline \multicolumn{5}{|c|}{ WST 9} \\
\hline 35 & 37 & 0.047 & 0.553 & " \\
\hline 37 & 38 & 0.05 & 0.503 & " \\
\hline 38 & 39 & 0.047 & 0.456 & “ \\
\hline 39 & 40 & 0.087 & 0.369 & " \\
\hline 40 & 41 & 0.044 & 0.325 & " \\
\hline 41 & 41 & 0.082 & 0.243 & “ \\
\hline 25 & 32 & 0.087 & 0.156 & " \\
\hline \multirow[t]{2}{*}{36} & 29 & 0.094 & 0.062 & " \\
\hline & & 0.538 & & \\
\hline
\end{tabular}

In Balancing of the Assembly Line, the line is said to be balanced when the workstations have approximately the same operation times allocated to each, for the output of the line is determined by the slowest operation. From Tables 2 and 3 , the ceiling fan motor assembly line is balanced. The output required from this line has been set at 800 complete assembled product of ceiling fan motor and accessories per day based on 480 useful minutes (i.e. 8 hours) per working period (shift).

Thus, Target cycle time, $\mathrm{c}=\frac{480}{800}=0.6 \mathrm{~min}$ 
Since all standard times are less than the cycle time $\left(t_{i}<c\right)$, then this cycle time is accepted. The sum of the standard element times equates to $4.987 \mathrm{~min}$.

The minimum number of workstation $\mathrm{n}_{\min }$ is $=\frac{4.987}{0.6}=9$ (to the next highest integer).

From Table 3, the actual cycle time is $=0.583 \mathrm{~min}$.

Therefore, the idle time in the balanced line is $=9 \times 0.583-4.987=0.26 \mathrm{~min}$.

Balance Delay (B.D) $=\frac{0.26 \times 100}{9 \times 0.58}=5 \%$.

Therefore, new line efficiency after balancing the line $=100-5=95 \%$. This gives a possible output of $\frac{480 \mathrm{~min}}{0.503 \mathrm{~min}}=823$ units of celling fan motor assembled product per shift.

\section{CONCLUSIONS}

In this study, time studies of ceiling fan motor production was done, examined with respect to assembly line balancing and data which are necessary for balancing obtained. The assembly line is said to be balanced when the workstations have approximately the same operation times allocated to each; for the output of the line is determined by the slowest operation. The balanced line for the ceiling fan motor assembly line is given in Table 3 with the target cycle time of 0.6 minutes and the actual cycle time of 0.583 min. On balancing the line by Rank Positional Weight (RPW) the actual cycle time was reduced from $0.729 \mathrm{~min}$ to $0.583 \mathrm{~min}$. Equally, the balanced line reduced the idle time from $2.23 \mathrm{~min}$ to $0.26 \mathrm{~min}$ and the balance delay from $31 \%$ to $5 \%$. The new line efficiency was increased from $69 \%$ to $95 \%$ thereby increasing the possible output from 608 units to 823 units per shift of 480 minutes. This shows an increase in productivity since more is produced within the same time without additional resources. Though RPW is a heuristic method, it offers practical tool especially in small scale manufacturing assembly line balancing problems where mathematically optimizing methods and other soft computing methods may be very expensive. It can readily be understood and applied from practical application viewpoint especially in societies like Nigeria where computer literacy is low.

\section{REFERENCES}

1. Amen, M., (2001), Heuristic methods for cost-oriented assembly line balancing; A comparison on solution quality and computing time. International Journal of Production Economic, 69 (3) 255-264.

2. Bhoyar, Sanjay and D. Parbat. "Repetitive project scheduling: developing CPM-like analytical capabilities." International Journal of Civil Engineering 3.5 (2014): 37-46.

3. Muhammad Razif Abdullah Make, MohdFadzilFaisae Rashid, Muhamad MagffierahRazali, ManugariPerumal (2017) Assembly Line Balancing using Heuristic Approaches in Manufacturing Industry; Journal of Mechanical Engineering Vol SI 4(2), pp 171-185.

4. Martino, L., Pastor, R., (2010), Heuristic procedures for solving the general Assembly line balancing problem with setups. Int. J Pro Res 48 (6); 1789-1804.

5. Yadav, Ashish, and Sunil Agrawal."A multi-manned parallel two-sided assembly line balancing with tool sharing approach-A company case study solved by exact solution approach." International Journal of Mechanical and Production Engineering Research and Development 9.2 (2019): 51-60.

6. Naveen Kumar and DalgobindMahto (2013) Assembly Line Balancing: A Review of Developments and Trends in Approach to Industrial Application; Global Journal of Researches in Engineering, Vol. XIII, Issue VII, pp 1-23. 
7. Becker, C., School, A., (2006), Survey on problems and methods in generalized assembly line balancing. European Journal of Operational Research, 168 (3), 694-715.

8. Khan, Mohd Salman, and Saurabh. Jha. "Evaluation of standard time with the application rank positional weighted method in the production line." Int J Mech Product Eng Res Develop 7.2 (2017): 73-80.

9. Tijo S., Numar R., (2008), Heuristic programming for assembly line balancing, In: Regional Conference of Mathematical Programming Seoul, pp. 226-230

10. McMullen, P.R., Fraizer, G.V., (2010), Using of simulated annealing to solve a multi-objective assembly line balancing problem with parallel workstation. International Journal of Production Research. 36 (10), 2717-2741. www. tanonline.com/doc/pelf/10.1080

11. AshkanHafezalkotob, Hamid Ketabian and HesamRahimi (2014) Balancing the Production Line by the Simulation and Statistics Techniques: A Case Study, Research Journal of Applied Sciences, Engineering and Technology 7(4): pp 754-763.

12. Sikora C. G. S., Lopes T. C., Schibelbain D., and Magatão L., (2017) "Integer based formulation for the simple assembly line balancing problem with multiple identical tasks,” Comput. Ind. Eng., 104, pp 134-144.

13. Senthilkumar, B., and H. Samuel Thavaraj. "An evaluation of TPM implementation in clothing industry in India-a lean philosophy based approach." International Journal of Industrial Engineering \& Technology (IJIET), 4 (6), 11 18 (2014).

14. Pape T., (2015) "Heuristics and lower bounds for the simple assembly line balancing problem type 1: Overview, computational tests and improvements,” Eur. J. Oper. Res., 240 (1), pp 32-42.

15. Boysen, N., Fliedner, M., School, A., (2007), A classification of assembly line balancing problem. European Journal of Operational Research, 183 (2), 674-693.

16. Hegde, Sharat S., SagarChakole, and VatsalVora. "Development of Self Balancing Robot With PID Control." International Journal of Robotics Research and Development (IJRRD) 7.1 (2017): 1-6.

17. Abdullah Make M. R., Ab. Rashid M. F. F., and Razali M. M., (2017) "A review of two-sided assembly line balancing problem,” Int. J. Adv. Manuf. Technol., 89 (5), pp 1743-1763.

18. Make M. R. A., Rashid M. F. F., and Razali M. M., (2016) "Modelling of Two-sided Assembly Line Balancing Problem with Resource Constraints,” IOP Conf. Ser. Mater. Sci. Eng., 160, 012005.

19. Tang Q., Li Z., and Zhang L., (2016) "An effective discrete artificial bee colony algorithm with idle time reduction techniques for two-sided assembly line balancing problem of type-II," Comput. Ind. Eng., 97, pp 146-156.

20. Razali M. M., Rashid M. F. F., and Make M. R. A., (2016) "Mathematical Modelling of Mixed-Model Assembly Line Balancing Problem with Resources Constraints," IOP Conf. Ser. Mater. Sci. Eng., 160, 012002.

21. Gonca, T., Seyda, T., (2013), Assembly line balancing with positional constraints, task assignment restrictions and station paralleling; A case in an electronics company. Computers and Industrial Engineering 101. 64, pp 602-609.

22. Hamza R. M. A. and Al-manaa J. Y., (2013) "Selection of Balancing Method for Manual Assembly Line of Two Stages Gearbox,” Glob. Perspect. Eng. Manag., 2 (2), pp 70-81.

23. Ghutukade S. T. and Sawant S. M., (2013) "Use of Ranked Position Weighted Method, Int. J. Adv. Eng. Res. Stud., pp 5-7.

24. Helgeson, W., Birnie, D., (1961), Assembly line balancing using Ranked Positional Weight (RPW) Technique, Journal of Industrial Engineering, 12, 394-398. 